\title{
Drinking During Pregnancy Decreases Word Attack and Arithmetic Scores on Standardized Tests: Adolescent Data From a Population-Based Prospective Study
}

\author{
Ann P. Streissguth, Helen M. Barr, Heather Carmichael Olson, Paul D. Sampson, Fred L. Bookstein, and Donna M. Burgess
}

\begin{abstract}
Women (1529) were interviewed in midpregnancy, and a cohort of their children has been examined at various ages. The two standardized tests presented herein are part of a large battery of tests administered when the children were 14 years old. "Word Attack" ( $n$ $=462$ ) measures phonological processing on a task involving the reading of pseudowords in nontimed performance. "Arithmetic" (n $=191$ ) measures auditorily processed mental computations in timed performance. Scores on both tests were associated with prenatal alcohol exposure in a dose-dependent fashion. These effects were robust when considered in relation to a wide variety of potentially confounding variables, such as prenatal exposure to tobacco and other drugs, sociodemographic characteristics, and traumatic postnatal events. A variety of alcohol scores were related to these two performance measures, but those involving a massing of drinks on a given occasion had the strongest association. The higher the average number of drinks/occasion, the poorer the offspring performance on tasks thought to underlie numerical problem solving and reading proficiency. Earlier reports of prenatal, alcohol-related neurobehavioral deficits in childhood have now been extended into adolescence.

Key Words: Fetal Alcohol Effects, Behavioral Teratology, Alcohol,
\end{abstract} Adolescence, Word Attack, Arithmetic, Learning Disabilities.

ONG BEFORE THE Surgeon General of the United States recommended not drinking alcohol during pregnancy or when planning a pregnancy, ${ }^{1}$ the National Institute on Alcohol Abuse and Alcoholism began funding several large-scale studies to examine the consequences to the offspring of maternal alcohol use during pregnancy. Only one of the original four studies begun before $1975^{2}$ is still continuing. The children in this study are now adolescents.

In this study, we present data from the 14-year wave of data collection from the Seattle Longitudinal Prospective

From the Departments of Psychiatry and Behavioral Sciences (A.P.S., H.M.B., H.C.O.), Statistics (P.D.S.), and Special Education (D.M.B.), University of Washington, Seattle, Washington; and the Center for $\mathrm{Hu}$ man Growth and Development (F.L.B.), University of Michigan, Ann Arbor, Michigan. 1993

Received for publication November 16, 1992; accepted August 18,

This research was supported primarily by Grant AA01455-01-17 from the National Institute on Alcohol Abuse and Alcoholism, U.S. Public Health Service.

Reprint requests: Ann P. Streissguth, Ph.D., Fetal Alcohol and Drug Unit, Department of Psychiatry and Behavioral Sciences, GG-20, University of Washington Medical School, Seattle, WA 98195.

Copyright (C) 1994 by The Research Society on Alcoholism.
Study on Alcohol and Pregnancy. The two tests described here were part of a large battery of tests administered at the 14-year exam. The goal of the 14-year wave of data collection was to study underlying deficits in attention, memory, cognitive and motor skills. The two tests described in this paper appear separately, because they differ from the other tests either conceptually or in sample size.

These two tests, "Word Attack" and "Arithmetic," are the only standardized tests of academic-type performance included in the 14-year examination. They are thought to measure important underlying components of learning. Word Attack involves the reading of pseudowords in nontimed performance, which taps the subject's ability to apply the pronunciation rules of the English language in approaching novel words that could not have been memorized from past experience or decoded by context. Pseudoword reading deficits are among the strongest persisting neurolinguistic deficits among adults who were childhood dyslexics. ${ }^{3}$ Some experts believe that the use of pseudowords constitutes the best way to measure reading skills. ${ }^{4}$ Detection of pseudoword reading deficits this late in development could have important implications for understanding the enduring effects of prenatal alcohol exposure on adolescent learning. The Arithmetic subtest from the Wechsler Intelligence Scale for Children-Revised (WISCR) measures auditorily processed mental computation in timed performance and is thought to tap underlying information processing strategies, as well as basic numerical skills. ${ }^{5}$ Previous decrements on this same arithmetic subtest, as well as on an additional arithmetic achievement test, were documented when these children were 7 years old. ${ }^{6-9}$ Detection of continuing deficits in numerical problem solving into adolescence also could have important implications for comprehending the long-term consequences of prenatal alcohol exposure.

\section{METHODS}

The Seattle Longitudinal Prospective Study on Alcohol and Pregnancy was initiated in 1974 to examine the long-term consequences to offspring of maternal drinking during pregnancy. Previous papers describe the study design. ${ }^{10-12}$ Two hospitals were selected for recruitment, which reflected the sociodemographic characteristics of the Seattle population at the time. All eligible consenting English-speaking women were ac- 
cepted for interview if they were receiving prenatal care by the 5th month of pregnancy and lived within a 20 -mile radius of Seattle. During a 1year period, 1529 women were given the 30 -min interview regarding health practices and pregnancy history that included detailed questions on beverage consumption, drugs, medications, and diet. The alcohol scores derived from this interview. All prenatal interviews were conducted in private in the women's homes by research assistants not associated with the hospitals.

\section{Subjects}

The follow-up cohort of $\sim 500$ offspring was selected at delivery from the 1529 previousiy interviewed mothers, on the basis of the earlier maternal report of alcohol and cigarette use during pregnancy. The follow-up sample was stratified for cigarette use across levels of alcohol use, and oversampled for heavier drinkers. Thus, the follow-up cohort included almost all of the offspring of the heavier drinkers from the interview sample, but a much smaller proportion of the very light drinkers' children. There were no exclusionary criteria for babies alive at discharge.

The mothers were basically a low-risk group of pregnant women. The nature of the original selection constrained the interview sample to mothers in prenatal care by midpregnancy, thereby restricting the entry of high-risk mothers without adequate prenatal care into the sample. The mothers were primarily White, married, well-educated, and middle-class. A unique window of opportunity permitted recruitment of a low-risk group of mothers who already knew not to smoke during pregnancy (only $29 \%$ of the interview sample smoked), but did not yet know about the risks of drinking during pregnancy ( $80 \%$ drank some alcohol during pregnancy and in the month or so prior to pregnancy recognition $\left.{ }^{11}\right)$. The prematurity rate ( $<37$ weeks) was only $4 \%$, and the low-birth weight rate $(<2500 \mathrm{~g})$ was only $3 \%$. At 7 years of age, $95 \%$ still lived with the biologic mother and $70 \%$ with the biologic father.

\section{Alcohol}

Alcohol use was assessed with a quantity-frequency-variability (QFV) interview supplemented with questions to enable reporting of over 5 drinks/occasion, as recommended by Room. " The interview was embedded in a general health interview; great care was taken to ensure a valid report. ${ }^{11}$ Alcohol scores were generated that reflected many dimensions of use including dose, frequency, pattern, and timing. ${ }^{11,13,14}$ Testretest reliability of the alcohol scores was high $(r=0.85-0.95)$ and comparable to those obtained for caffeine scores. ${ }^{.1}$ The alcohol interview and quantification system were considered state-of-the-art at the time they were implemented in 1974 and based on those used in a similar study. ${ }^{15}$ Questions were first asked about drinking "during pregnancy" (which at the time of interview was the beginning of the 5th month). Separate questions were asked for wine, beer, and liquor. Then the same questions were asked for the month or so prior to pregnancy or pregnancy recognition, in an effort to document use during the early period of embryogenesis so critical to the study of teratogens. Women were not interviewed regarding their alcohol use during the last half of pregnancy.

For the present set of analyses, the same basic alcohol scores were examined that have been examined in other recent papers. ${ }^{6-10,16,17}$ The scores listed in Table 1 include general volume measures [average oz of absolute alcohol/day (calculated according to Jessor et al. ${ }^{18}$ ) and a QFV index (calculated according to Cahalan et al. ${ }^{13}$ )], a measure of frequency of alcohol use (monthly occasions of drinking), and three "binge" measures of massed drinking (average drinks/occasion, maximum drinks/ occasion, and ever drinking 5 or more drinks on any occasion in the designated time period). A dichotomous score for abstaining in both time periods was also included. Unless otherwise noted, these scores were calculated according to self-report for the two time periods studied.

\section{Procedures}

Contact with the cohort families was maintained through special procedures developed by the investigators for longitudinal research. ${ }^{19}$
Table 1. Correlations Among Maternal Alcohol Scores and Word Attack and Arithmetic Scores (Including Distribution Statistics on Alcohol Scores)

\begin{tabular}{|c|c|c|}
\hline & $\begin{array}{l}\text { Word Attack } \\
(n=462)\end{array}$ & $\begin{array}{c}\text { Arithmetic } \\
(n=191)\end{array}$ \\
\hline \multicolumn{3}{|l|}{ Average oz absolute alcohol/day (AA) } \\
\hline $\begin{array}{l}\text { Prepregnancy recognition }(n=338 ; 0.01-25.76 \\
0 z ; \text { median }=0.41)\end{array}$ & $-0.1282^{*}$ & -0.0643 \\
\hline $\begin{array}{l}\text { During pregnancy }(n=359: 0.01-8.55 \mathrm{oz} \text {; me- } \\
\qquad \text { dian }=0.16)\end{array}$ & -0.0677 & -0.0950 \\
\hline \multicolumn{3}{|l|}{ Average monthly occasions of drinking (MOCC) } \\
\hline $\begin{array}{l}\text { Prepregnancy recognition }(n=338: 0.3-240 \\
\text { times; median }=9.0)\end{array}$ & $-0.1140 \dagger$ & -0.0480 \\
\hline $\begin{array}{l}\text { During pregnancy }(n=359: 0.3-105 \text { times; me- } \\
\text { dian }=4.5 \text { ) }\end{array}$ & -0.0726 & -0.0574 \\
\hline \multicolumn{3}{|l|}{ QFV Index } \\
\hline $\begin{array}{l}\text { Prepregnancy recognition ( } n=338: 2-5 ; 5= \\
\text { heaviest; median }=3 \text { ) }\end{array}$ & $-0.1272^{*}$ & -0.1341 \\
\hline $\begin{array}{l}\text { During pregnancy }(n=359: 2-5 ; 5=\text { heaviest; } \\
\qquad \text { median }=3 \text { ) }\end{array}$ & $-0.1220^{*}$ & -0.1096 \\
\hline \multicolumn{3}{|l|}{ Average drinks/occasion (ADOCC) } \\
\hline $\begin{array}{l}\text { Prepregnancy recognition }(n=338: 1.5-13 \\
\text { drinks; median = 2.2) }\end{array}$ & $-0.1513^{*}$ & $-0.1542 \dagger$ \\
\hline $\begin{array}{l}\text { During pregnancy }(n=359: 1.5-13 \text { drinks; me- } \\
\text { dian }=1.8 \text { ) }\end{array}$ & $-0.1390^{*}$ & -0.1247 \\
\hline \multicolumn{3}{|l|}{ Maximum drinks any occasion (MAX) } \\
\hline $\begin{array}{l}\text { Prepregnancy recognition ( } n=338: 1.5-13 \\
\text { drinks; median }=3.5 \text { ) }\end{array}$ & $-0.1498^{*}$ & $-0.1479 \dagger$ \\
\hline $\begin{array}{l}\text { During pregnancy }(n=359: 1.5-13 \text { drinks; me- } \\
\text { dian }=3.5 \text { ) }\end{array}$ & $-0.1161 \dagger$ & $-0.1441 \dagger$ \\
\hline \multicolumn{3}{|l|}{5 or more drinks on any occasion (BINGE $\geq 5$ ) } \\
\hline $\begin{array}{l}\text { Prepregnancy recognition ( } n=338: 0-1 \text {; me- } \\
\quad \text { dian }=0)\end{array}$ & $-0.1497^{*}$ & $-0.1514 \dagger$ \\
\hline During pregnancy $(n=359: 0-1 ;$ median $=0)$ & $-0.1193+$ & $-0.1460 \dagger$ \\
\hline $\begin{array}{l}\text { Ordered exposure categories ( } n=368: 1-4 ; 4= \\
\text { heaviest; median }=3 \text { ) }\end{array}$ & $-0.1309^{\circ}$ & -0.1087 \\
\hline $\begin{array}{l}\text { Abstaining pre and during pregnancy ( } n=462 \text { : } \\
20 \% \text { abstained pre and during) }\end{array}$ & $0.0984 \dagger$ & $0.1543+$ \\
\hline
\end{tabular}

Note: For the analyses presented herein, all scores except the QFV Index, ORDEXC, and Abstainer Terms were log-transformed. There are no missing data; discrepancies in " $n$ ' $s$ " refer to the omission of abstainers for calculation of distribution statistics only. "Significance at $p \leq 0.01$ (2-tailed); † significance at $p \leq 0.05$ (2-tailed). For the distribution statistics for each alcohol score, shown in parentheses for each time period, the observed range and median of the untransformed scores are presented for only those mothers who reported drinking during the designated time period. Alcohol statistics omit the 124 mothers (of 462) who abstained in the prepregnancy recognition period and the 103 mothers (of 462) who abstained in the during pregnancy period. Correlations are computed with abstainers and drinkers combined.

The 464 singleton-born participants in the 14-year exam represented an $82 \%$ follow-up of the original birth cohort. There was not a significantly greater loss to follow-up of children of heavier drinkers compared with the rest of the cohort. Moving out of area was the most frequent cause of loss to follow-up. Ninety-three percent of the subjects seen at the 7year exam were seen again at 14 years. All data were gathered blind, with examiners having no knowledge of maternal history or subject performance on previous examinations. All tracing, scheduling, and transporting of subjects was conducted by an outreach worker who did not examine the adolescents.

\section{Dependent Variables}

Two outcomes were examined for the present study. The Word Attack subtest of the Woodcock Reading Mastery Tests ${ }^{20}$ measures subject ability to read pseudowords. This ability requires the application of 
phonic and structural analysis skills ${ }^{20}$ to pronounce unfamiliar words. The test may also be used as a measure of auditory processing, according to Siegel and Heaven. ${ }^{4}$ Data on Word Attack were obtained for the full sample of 462. The Arithmetic Subtest of the Wechsler Intelligence Scale for Children-Revised ${ }^{21}$ was initiated midway through testing $(n=191)$, because it was felt to be important, and the overall examination time had decreased with examiner proficiency. This test measures numerical reasoning ability and auditorily processed mental computation. ${ }^{5}$ During the course of testing, four examiners collected these data. Despite careful standardized training and reliability checks, there remained some significant examiner effects on the two test scores.

\section{Covariates}

A large number of covariates were collected throughout the duration of the study to evaluate possible confounding effects: 150 of these were described previously along with our method and rationale for examining them in relation to the outcomes. ${ }^{12}$ Some of the primary covariates obtained at the time of the prenatal interview included: other prenatal ingestants [caffeine, cigarettes, all other drugs and medications, food (diet)]; sociodemographic and personal characteristics (maternal and paternal race, age, education, occupation, marital status, height, and weight); household information (number of children above and below 5 years of age; number of adults in household); and maternal obstetric history (parity, gravidity, history of pregnancy complications, and deceased children). Covariates obtained from medical records included number of prenatal visits, pregnancy and delivery complications, infant size parameters, delivery medications, problems with infant at birth, etc. Additional information obtained at later exams included breast feeding and nutrition of child, illnesses, fevers and hospitalizations, parent/child separations, maternal working status, mother-child interactions, status of the home environment, major life changes in household, marital status of parents, caretaking arrangements, preschool, day care attendance, etc. Situational factors were aiso studied at each data collection wave, including time of day, day of week, sleep, food, medications and alcohol/drug use prior to testing, sensory impairments that could influence performance, identity of examiner, and temperature of examination room.

\section{Statistical Analysis}

Statistical analysis involved five procedures: (1) correlational study of the 14 alcohol scores with the two performance measures; (2) study of possible confounding influences of covariates; (3) calculation of partial $t$ tests for alcohol, adjusting for appropriate covariates; (4) statistical checks on the regression assumptions; and (5) correlational study of the two 14year outcomes against selected data from the 7-year examination. All $p$ values were two-tailed to provide more conservative tests.

1. The relationship between the 14 alcohol scores and the 2 adolescent outcomes was examined with Pearson product-moment correlations. These are presented in Table 1 .

2. To help verify that significant simple correlations were not really attributable to other confounding factors, multiple regression was used to confirm what the simple correlations appeared to indicate. To determine the primary predictors for each outcome, correlational analyses were conducted between a large list of covariates, ${ }^{12}$ the two adolescent performance measures, and the alcohol scores that showed the strongest relationship to these performance measures. Appropriate regression models were developed to determine the set of covariates that best predicted each of the adolescent outcomes (see "Results"). Despite careful reliability checks among examiners, some had systematically deviant scores; as is customary in large-scale studies, an indicator was entered into the regression analyses for these examiners, henceforth referred to as dummy indicators for individual examiners. For Word Attack, the primary predictors included weight gain during pregnancy, sex, race, socioeconomic status, and a dummy indicator for an examiner. For Arithmetic, the primary predictors were maternal education and a dummy indicator for first-born status and a dummy indicator for an examiner. Once these primary predictors were in the regression models, no other covariates contributed "significantly." The variables with $t$ 's too low to enter included cigarette smoking, use of other drugs and medications, and other demographic characteristics, such as marital status.

3. After establishment of the basic model for each outcome, the alcohol score was entered, and partial $t$ tests were calculated, adjusting for all other variables in the model. These calculations were conducted with all of the alcohol scores listed in Table 1.

4. Additional checks on the regression assumptions were made. These included added variable plots with scatterplot smoothers, ${ }^{22,23}$ affirming that the adjusted data are approximately linear in a logarithmically scaled measure of alcohol consumption (log average number of drinks/occasion) and replication of the final model omitting potentially influential subjects and outliers. Many interaction terms involving the alcohol scores were examined to determine whether any modifications were necessary in the interpretation of these main effects. None of the terms considered in this exploratory analysis substantially altered the apparent statistical significance or interpretation.

5. To assess the longitudinal context of these findings, the two adolescent outcomes were correlated with relevant performance data from the 7 year follow-up, and low individual scores were examined in relation to prenatal alcohol exposure.

\section{RESULTS}

As Table 1 indicates, almost all the measures of prenatal alcohol exposure are statistically significantly related to Word Attack scores. The correlations of Alcohol with Arithmetic scores place relatively greater emphasis on the binge-oriented measures of consumption. Not as many predictors of Arithmetic scores are significant due to the smaller data set.

As the best single alcohol score for prediction of these two outcomes is "ADOCC-P" (Average Drinks/Occasion, Prior to Pregnancy Recognition), the regression analysis for this score is presented herein. The range of values for ADOCC-P is from 0 to 13 drinks/occasion, with the median being 1.5. (Among drinkers, the median was 2.2.) The multiple regression analysis of Word Attack included the following terms in the model: Alcohol (ADOCC-P, log-transformed to reduce the effect of extreme values), weight gain, sex of child, socioeconomic status, race, and a dummy indicator for an examiner. A partial $t$ test of the alcohol main effect, adjusting for the other independent variables, yielded a $t$ value -3.20 and a $p$ value of 0.002 . The partial correlation of alcohol with Word Attack resulting from this regression is -0.148 . Compared with the simple correlation of -0.151 , almost no change is observed as a result of adjusting for covariates.

A similar multiple regression model was developed for the prediction of Arithmetic by Alcohol. Partial $t$ tests for ADOCC-P, adjusting for each of the other independent variables in the model (namely, a dummy indicator for firstborn status, maternal education, and a dummy indicator for an examiner) yielded an alcohol partial correlation of -0.165 , partial $t=2.27, p=0.024$, even with the smaller sample size. As for Word Attack, there is no change in the basic interpretation of the Arithmetic findings as a result of adjustment for covariates. 
Main effects were thus observed for both Word Attack and Arithmetic, and appear to be stable even in replications of the analysis omitting outliers and potentially influential subjects. Data presented in Fig. 1, a and b, are for the "net" impact of alcohol after adjusting for the relevant covariates (previously described). However, the figures are little changed from corresponding scatterplots for unadjusted scores. The clear downward slope seen in the two figures indicates that increasing maternal alcohol use is related to poorer Word Attack and Arithmetic performance in 14-year-old offspring. Average Word Attack and Arithmetic scores for adolescents exposed to $>1.5$ drinks/occasion in early gestation are $\sim 1 / 3$ standard deviation lower than scores of abstainers' children.

The alcohol effects on these adolescent performance

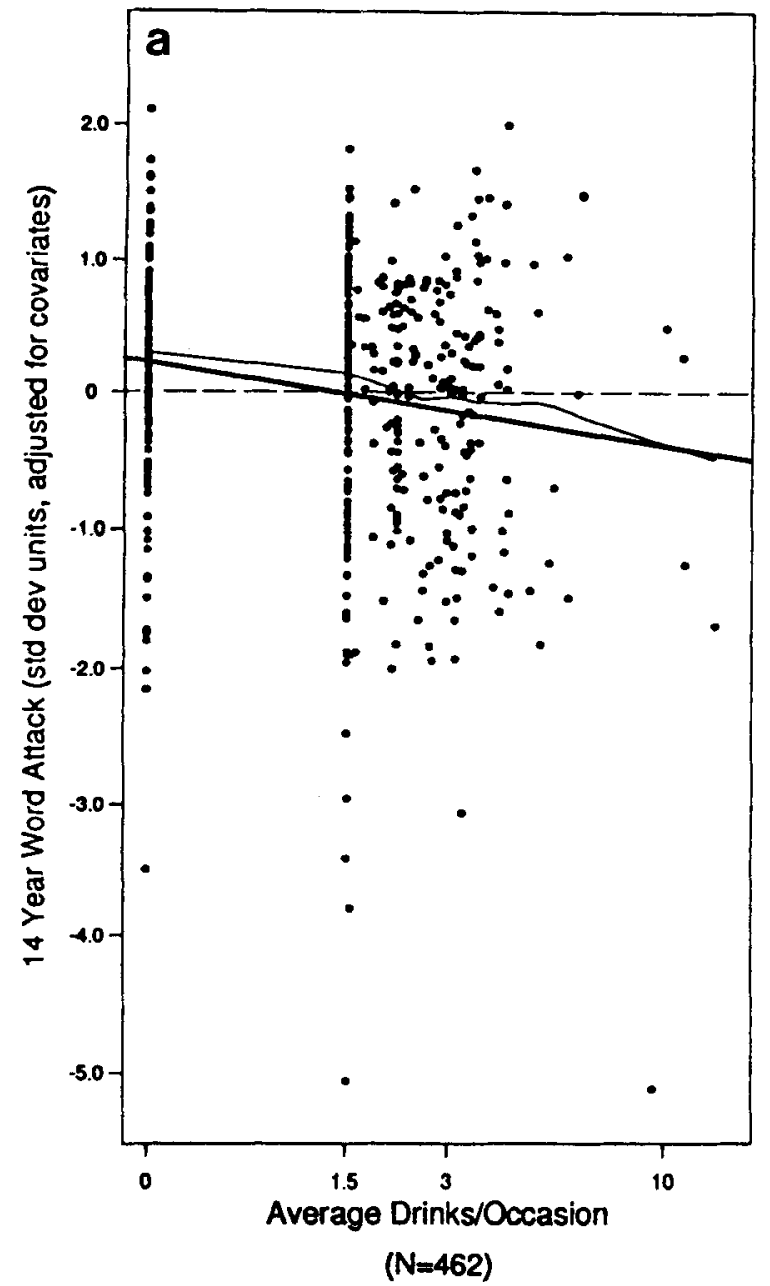

measures are not only robust against the possible confounding influence of covariates, but they also show substantial association with previously measured performance. Of the 191 subjects who received WISC-R Arithmetic at age 14 years, 180 had previously received WISC-R Arithmetic at age 7 years. WISC-R Arithmetic at 14 years was significantly correlated with WISC-R Arithmetic at 7 years $(r=0.492)$, and with Wide Range Achievement Test-Revised (WRAT-R) Arithmetic at 7 years $(r=0.441)$. Word Attack was only given at age 14 , but Word Attack at 14 years was significantly correlated with WRAT-R Reading at 7 years $(r=0.550)$. Table 2 compares WISC-R Arithmetic scores of the children at ages 7 and 14 years, categorized according to levels of prenatal alcohol exposure. When we compare the stability

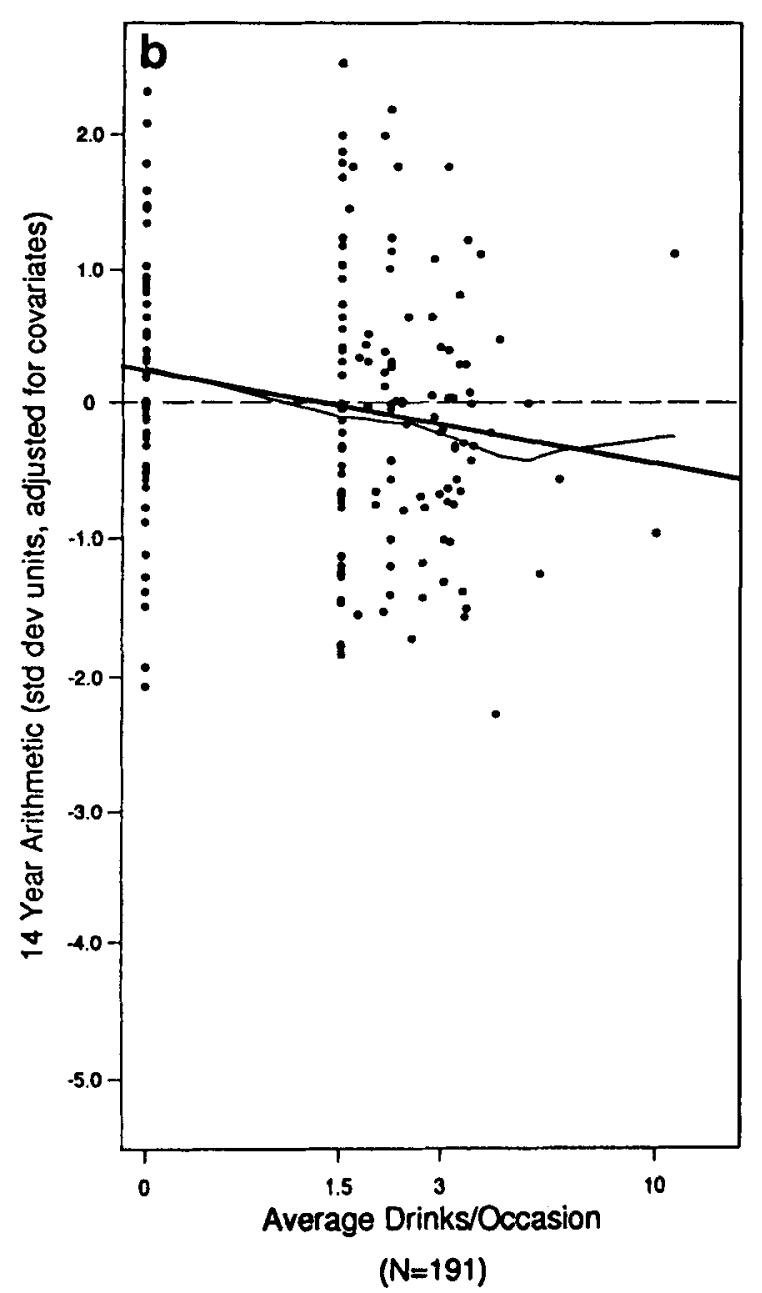

Fig. 1. ( $\mathrm{a}$ and b) Dose-response curve and associated scatterplots: adolescent performance by prenatal alcohol. These data show the monotonic relationship between prenatal alcohol exposure and offspring Word Attack and Arithmetic scores at 14 years of age, after adjusting for relevant covariates. The higher the exposure, the greater the effect, with no apparent threshold beyond the no alcohol level. In these scatterplots, Word Attack and Arithmetic are adjusted for covariates (see text) and standardized for plotting. The horizontal axis represents Alcohol scaled as the log of (average drinks/occasion +1 ). Although this graph reflects alconol intake prior to pregnancy recognition, analysis using the during-pregnancy score is substantially identical (see Table 1). The dashed horizontal line at 0 indicates the mean for this cohort. The light and irregular line represents a "lowess" scatterplot smoother ${ }^{22,23}$ that supports the appropriateness of fitting log average drinks/occasion as a linear effect. The dark solid line is the partial regression line according to the multiple regression described in the text. The scatterplot smoother lies entirely above the regression line in (a), because "lowess" is relatively resistant to the influence of the relatively extreme (low) Word Attack scores that pull the regression line down. The clear downward slope indicates that increasing alcohol is related to poorer scores on Word Attack and Arithmetic. The gap in alcohol scores between 0 and 1.5 is due to the construction of the QFV interview, which combines 1-2 drinks/occasion as the lowest positive score (herein averaged as 1.5 drinks). Thus, the black stripe of dots at 1.5 indicates mothers who say they never drank $>1$ or 2 drinks/occasion of any alcoholic beverage. This plot indicates that drinking even 1 or 2 drinks at a time and never more is associated with poorer performance on these two tests given at 14 years. 
Table 2. Arithmetic Scores of 7- and 14-Year-Old Children Categorized According to Prenatal Alcohol Exposure $(n=180)$

\begin{tabular}{|c|c|c|c|c|}
\hline Prenatal alcohol exposure & $\begin{array}{l}\text { Median drinks/ } \\
\text { occasion }\end{array}$ & $\begin{array}{l}\text { Total in } \\
\text { alcohol } \\
\text { group }\end{array}$ & $\begin{array}{c}\text { Total with low } \\
\text { Arithmetic at } \\
7 \text { years }\end{array}$ & $\begin{array}{l}\text { Total still having } \\
\text { low Arithmetic } \\
\text { at } 14 \text { years }\end{array}$ \\
\hline Abstainer & 0 & 55 & $22 / 55 \quad(40 \%)$ & $10 / 22(45 \%)$ \\
\hline Average 1-3.3 drinks/occasion & 1.9 & 106 & $48 / 106(45 \%)$ & $32 / 48(67 \%)$ \\
\hline Average 3.4 or more drinks/occasion & 3.7 & 19 & $11 / 19(58 \%)$ & $10 / 11(91 \%)$ \\
\hline Total & 1.5 & 180 & $81 / 180(45 \%)$ & $52 / 81(64 \%)$ \\
\hline
\end{tabular}

Note: Of the 191 subjects with valid 14-year WISC-R Arithmetic data, 180 had valid WISC-R Arithmetic data at 7 years. Scores on this variable range from 0 to 20. The median Arithmetic scores at 7 and 14 years are 10 and 11, respectively. Low Arithmetic = Arithmetic below the median at 7 years (Arithmetic score < 10). Average 3.4 or more drinks/occasion (ADOCC $\geq 3.4$ ) $=$ the top $10 \%$ of the sample.

of low Arithmetic scores at 7 years, we find that of the 81 children with low Arithmetic scores (below the median) at 7 years, 52 (or $64 \%$ ) remained low on Arithmetic at 14 years. As Table 2 indicates, only $45 \%$ of the abstainers' children who scored low on Arithmetic at age 7 remained low on Arithmetic at 14 years. By comparison, $91 \%$ of the heavier drinkers' children who had scored low on Arithmetic at 7 years remained low on Arithmetic at 14 years.

\section{DISCUSSION}

This study deals with two tests from the research battery administered at the 14-year wave of data collection in this longitudinal prospective study of the long-term consequences of maternal alcohol use during pregnancy. One important new finding from this study is that the consequences of maternal drinking during pregnancy are still measurable 14 years later as performance deficits of exposed children. In other words, the prenatal alcohol effects on child performance, documented at many previous ages of development in this cohort, are not "washing out" as the children reach adolescence. This study is a harbinger of complex multivariate analyses to follow that consider many correlated alcohol exposure patterns, outcome scores from other 14-year tests, and measurements from earlier waves of assessment.

The present analyses indicate that prenatal alcohol exposure is related to adolescent Word Attack and Arithmetic performance in a dose-dependent fashion: the higher the exposure, the larger the performance deficits. The magnitude of these effects is in the range of $1 / 3$ of a standard deviation for each outcome at an exposure level of 1.5 drinks/occasion on the average. Children of abstainers have the best scores on both measures. These alcohol effects remain statistically significant after adjustment for appropriate covariates. Arithmetic scores, which were measured on the same task at ages 7 and 14 , remain significantly correlated across this 7-year span. Some continuity of performance for individual children is also noted, in that children who were low on Arithmetic at 7 years were more likely to remain low at 14 years, if their mothers had been among the heavier drinkers $(91 \%$ continued to have low scores) compared with those whose mothers had been abstainers (only $45 \%$ continued to have low scores).

Rather than reflecting academic achievement per se, both of these tests are thought to measure underlying processes that are important for the acquisition of reading and arithmetic skills. The WISC-R Arithmetic subtest is often interpreted as a test of problem-solving ability and of the ability to integrate verbal information presented in a mathematical context. ${ }^{5}$ Word Attack measures the phonological processes thought to underlie basic reading skills. Deficits in phonological processing are an important basis of reading problems. ${ }^{24}$ Performance on Word Attack is thought to represent a more biologic aspect of reading skill than are the skills tapped by the content of ordinary reading tests. Word Attack is one of the few reading tasks not confounded with other dimensions of reading such as guessing from content, guessing from past experience with certain words, etc. ${ }^{4}$ which may explain why the findings in the present study are relatively resistant to usual covariate influences. Reading disabled children perform poorly on Word Attack regardless of IQ level. ${ }^{25}$ In this study, word recognition scores, as measured on the WRAT at age 7 years, are significantly correlated with Word Attack scores at 14 years, $(r=0.55)$.

Although the present study only used the Word Attack test at age 14, this may be a useful outcome measure for studies of prenatal alcohol effects in younger children. Word Attack skills may also hold potential for early remedial interventions with young children with fetal alcohol effects who have reading problems. Word Attack skills have been the target of successful remediation programs in young children ${ }^{26,27}$ even though poor readers were not brought up to the level of good readers. ${ }^{28,29}$ Word Attack is one of the few neurolinguistic tasks that has been found to be related to neuroanatomical correlates. ${ }^{30}$

As Table 1 indicates, all of the prenatal alcohol measures studied showed statistically significant relationships with at least one of the outcome scores. As these dose measures all reflect, to varying extents, the same individual drinking behaviors, they are highly correlated with each other, and no one of them can be considered as the "true" dose. In the present analyses, those drinking patterns having to do with a "massed" pattern of drinking are, in general, more strongly correlated with the outcomes than scores reflecting the frequency of drinking occasions or "average" daily patterns. This is congruent with other reports from this study ${ }^{7-10,17}$ after the children were over 7 years old. Massed drinking would be expected to have more of an impact on blood alcohol level, which in turn has been shown in 
animal studies to be more important than administered "dose" in the production of fetal alcohol effects in offspring. Recent work by West et al. ${ }^{31}$ has shown that "bingetype" exposure patterns produced stronger offspring effects than the same amount of alcohol presented regularly throughout the day. This is not to say that frequency of use is not associated with child outcomes (see Table 1), but rather to say that among the dose measures studied herein, with these outcomes and in these adolescent offspring, that the massed drinking scores produce the strongest correlations.

Likewise, it is not possible to say from these data that drinking only during one part of pregnancy versus another is producing the effects reported. Drinking during the third trimester was not even measured, and ADOCC-P and ADOCC-D were highly correlated at $r=0.800$. The ADOCC-P scores were selected for the graphical presentation, because they showed a stronger relationship to these outcomes than the ADOCC-D scores, but the latter were also significantly related to poorer performance (see Table 1).

In examining behavioral outcomes of teratogens, it is, of course, important to consider the various types of postnatal influences that also impinge on a child's development. As previously described, a wide variety of postnatal environmental variables are routinely considered in our analyses as potential covariates. But because many potentially confounding influences were controlled through original study design and sample selection, our data set circumvents many of the biases that often interfere with inference in nonexperimental studies. Maternal and paternal education are almost always the strongest predictors of child behavioral variables, and this study is no exception. However, once we have adjusted for either of these, other covariates show little further effect on outcomes.

Two potential covariates that are sometimes considered in other studies are absent from our study by design (parental IQ and maternal postnatal drinking). Parental IQ was not included because it was not feasible within the constraints of the study to obtain 1000 parental IQ tests. This is not a serious problem, however, as the correlation of our maternal and paternal education scores with child IQ are at least as good as those reported in the literature between parental IQ and child IQ. ${ }^{32}$

Although literature certainly exists on the adverse effects of parental alcoholism on children, ${ }^{33}$ studying them in an alcohol teratology study is difficult due to the high correlation between prepregnancy recognition drinking and postnatal drinking. The best way to tease out these effects in studies of alcohol teratogenesis is through study design, not through post-hoc "statistical" adjustment. The type of high-risk alcoholic mother without adequate prenatal care, who might be suspected of providing the most adverse postnatal environment for the child, was systematically excluded from our study by the design feature requiring prenatal care by the 5th month of pregnancy. Less than $1 \%$ of the mothers in our study reported any major alcohol problems. Were they in denial? We cannot say, but we can say that $80 \%$ of the mothers interviewed readily admitted to drinking during pregnancy. Demographically, these women are representative of Seattle area mothers in the early 1970s. Their drinking habits were characteristic of Seattle women in an era when it was not known that "social" levels of drinking could have deleterious effects on offspring. Rather than using a postnatal maternal drinking score as a marker for an adverse environment, our analytic plan has involved the evaluation of many important environmental variables that might have a direct effect on child development (mother-child interactions, major life changes in the household, parental education, family constitution, etc.). The prenatal alcohol effects reported herein were not found to be attributable to these environmental covariates.

This study of the relationship of prenatal alcohol exposure to adolescent outcomes extends and enhances earlier findings from this project, including alcohol-related decrements in achievement (especially arithmetic), classroom behavior, and information processing based on teacher reports when the children were 11 years old. ${ }^{17}$ Prenatal alcohol exposure was also related to childhood neurobehavioral deficits at 4 and 7 years and to academic achievement and classroom performance at 7 years. ${ }^{6-10,32,34,35}$ Although one study has not detected neurobehavioral alcohol effects in the preschool years, ${ }^{36,37}$ reports from other studies do show alcohol-related cognitive, academic, or neurobehavioral outcomes in 4- to 7-year-old children (e.g., refs. 38 and 39). Many design features contribute to positive and negative results in alcohol teratology studies. These include power of the study design (in terms of the number of heavier drinking mothers, their levels of consumption, and the relative confounding of drinking with other important covariates), precision of estimating both the independent and the dependent variables, and the success of following-up the sample, especially the offspring at highest risk for prenatal alcohol effects.

Word Attack and Arithmetic decrements continuing into adolescence may well indicate basic biologic information processing deficits that could contribute to an increase in school-related problems during the adolescent years. Subsequent reports will examine additional adolescent sequelae of prenatal alcohol exposure within the rich context of a multivariate data set.

\section{ACKNOWLEDGMENTS}

\footnotetext{
We gratefully acknowledge the original coinvestigators: Donald $\mathrm{C}$. Martin, Biostatistician, and Joan C. Martin, Experimental Psychologist, as well as Ruth E. Little, Sc.D., Epidemiologist, who together made important contributions to the study design. We acknowledge the dedicated work of the following research assistants: Mike Scott, Julie Feldman, Jeanne Gray, Natasha Grossman, Patricia Barron, and Tracy Smith. Cara C. Ernst is thanked for manuscript preparation and technical assistance. Karen Kopera-Frye, Ph.D., made valuable contributions to
} 
manuscript critique and review. The authors also acknowledge the contributions of the grant reviewer, Linda Siegel, Ph.D., who suggested that "Word Attack" be included in the 14-year data collection. Above all, we thank the 464 families who have made this study possible.

\section{REFERENCES}

1. Surgeon General's Advisory on Alcohol and Pregnancy: FDA Drug Bulletin, 11 (2). Rockville, MD, Department of Health and Human Services, 1981

2. Streissguth AP, Landesman-Dwyer S, Martin JC, Smith DW: Teratogenic effects of alcohol in humans and laboratory animals. Science 209:353-361, 1980

3. Bruck M: Word-recognition skills of adults with childhood diagnosis of dyslexia. Dev Psychol 26:439-454, 1990

4. Siegel LS, Heaven RK: Categorization of learning disabilities, in Ceci SJ (ed): Handbook of Cognitive, Social, and Neuropsychological Aspects of Learning Disabilities, vol 1, chap 4. Hillsdale, NJ, Lawrence Erlbaum Associates, 1986, pp 95-122

5. Sattler JM: Assessment of Children, ed 3. San Diego, Jerome M. Sattler, Publisher, 1988

6. Streissguth AP, Barr HM, Sampson PD, Bookstein FL, Darby BL: Neurobehavioral effects of prenatal alcohol. Part I. Research strategy. Neurotoxicol Teratol 11:461-476, 1989

7. Sampson PD, Streissguth AP, Barr HM, Bookstein FL: Neurobehavioral effects of prenatal alcohol. Part II. Partial least squares analysis. Neurotoxicol Teratol 11:477-491, 1989

8. Streissguth AP, Bookstein FL, Sampson PD, Barr HM: Neurobehavioral effects of prenatal alcohol. Part III. PLS analyses of neuropsychologic tests. Neurotoxicol Teratol 11:493-507, 1989

9. Streissguth AP, Barr HM, Sampson PD: Moderate prenatal alcohol exposure: Effects on child IQ and learning problems at age $71 \frac{1}{2}$ years. Alcohol Clin Exp Res 14:662-669, 1990

10. Streissguth AP, Barr HM, Bookstein FL, Sampson PD: The Enduring Effects of Prenatal Alcohol Exposure on Child Development. Birth Through 7 years: A Partial Least Squares Solution. Ann Arbor, MI, University of Michigan Press, 1993

11. Streissguth AP, Martin DC, Martin JC, Barr HM: The Seattle longitudinal prospective study on alcohol and pregnancy. Neurobehav Toxicol Teratol 3:223-233, 1981

12. Streissguth AP, Sampson PD, Barr HM, Clarren SK, Martin DC: Studying alcohol teratogenesis from the perspective of the fetal alcohol syndrome: Methodological and statistical issues, in Wisniewski HM, Snider DA (eds): Mental Retardation: Research, Education, and Technology Transfer, vol 477. New York, Academy of Sciences, 1986, pp 63-86

13. Cahalan D, Cissin IH, Crossley HM: American Drinking Practices: A National Study of Drinking Behavior and Attitudes (Monograph no. 6). New Brunswick, NJ, Rutgers Center of Alcohol Studies Publications, 1969

14. Room R: Asking about amount of drinking. Drinking, Drug Pract Survey 1:16, 1970

15. Little RE: Moderate alcohol use during pregnancy and decreased infant birth weight. Am J Publ Health 67:1154-1155, 1977

16. Streissguth AP, Sampson PD, Carmichael Olson H, Bookstein FL, Barr HM, Scott M, Feldman J, Mirsky AF: Maternal drinking during pregnancy: Attention and short-term memory in 14-year-old offspring: A longitudinal prospective study. Alcohol Clin Exp Res 18:202-218, 1994

17. Carmichael Olson H, Sampson PD, Barr H, Streissguth AP, Bookstein FL: Prenatal exposure to alcohol and school problems in late childhood: A longitudinal prospective study. Development and Psychopathology 4:341-359, 1992

18. Jessor R, Graves TD, Hanson RC, Jessor SL: Society, Personality, Deviant Behavior: A Study of a Tri-ethnic Community. New York, Holt, Rinehart, Winston, 1968
19. Streissguth AP, Giunta CT: Subject recruitment and retention for longitudinal research: Practical considerations for a nonintervention model, in Kilbey MM, Asghar K (eds): Methodological Issues in Epidemiological, Prevention, and Treatment Research on Drug-Exposed Women and Their Children. National Institute on Drug Abuse Monograph no. 117. Rockville, MD, U.S. Department of Health and Human Services, 1992

20. Woodcock RW: Woodcock Reading Mastery Tests-Revised. Circle Pines, MN, American Guidance Service, 1987

21. Wechsler D: The Wechsler Intelligence Scale for Children, Revised. New York, The Psychological Corporation, 1974

22. Chambers JM, Cleveland WS, Kleiner B, Tukey PA: Graphical Methods for Data Analysis. Belmont, CA, Wadsworth, 1983

23. S-PLUS User's Manual, version 3.0. Seattle, WA, Statistical Sciences, Inc., 1991

24. Rack JP, Snowling MJ, Olson RK: The nonword reading deficit in developmental dyslexia: A review. Reading Res Q 27:28-53, 1992

25. Siegel LS: IQ and learning disabilities: R.I.P., in Swanson HL, Keogh B (eds): Learning Disabilities: Theoretical and Research Issues. Hillsdale, NJ, Lawrence Erlbaum Associates, 1990

26. Mantzicopoulos P, Morrison D, Stone E, Setrakian W: Use of the SEARCH/TEACH tutoring approach with middle-class students at risk for reading failure. Elementary School J 92:573-586, 1992

27. Brown IS, Felton RH: Effects of instruction of beginning reading skills in children at risk for reading disability. Reading \& Writing 2:223241,1990

28. Rubin H, Rotella T, Schwartz L, Bernstein S: The effect of phonological analysis training on naming performance. Reading \& Writing 3:1-10, 1991

29. Kuder SJ: Effectiveness of the DISTAR reading program for children with learning disabilities. J Learning Disabil 23:69-71, 1990

30. Semrud-Clikeman M, Hynd GW, Novey ES, Eliopulos D: Dyslexia and brain morphology: Relationships between neuroanatomical variation and neurolinguistic tasks. Learning \& Individual Differences 3:225-242, 1991

31. West JR, Goodlett CR, Bonthius DJ, Pierce, DW: Manipulating peak blood alcohol concentrations in neonatal rats: Review of an animal model for alcohol-related developmental effects. Neurotoxicology 10:347-366, 1989

32. Streissguth AP, Barr HM, Sampson PD, Darby BL, Martin DC: IQ at age 4 in relation to maternal alcohol use and smoking during pregnancy. Dev Psychol 25:3-11, 1989

33. Scher KJ: Children of Alcoholics: A Critical Appraisal of Theory and Research. Chicago, University of Chicago Press, 1991

34. Streissguth AP, Barr HM, Martin DC: Alcohol exposure in utero and functional deficits in children during the first four years of life, in Porter R, O'Connor M, Whelan J (Eds): CIBA Foundation Symposium 105: Mechanisms of Alcohol Damage in Utero. London, Pitman, 1984, pp 176-196

35. Carmichael Olson H. Streissguth AP, Bookstein FL, Barr HM, Sampson PD: Developmental research in behavioral teratology: The impact of prenatal alcohol exposure on child development, in Friedman SL, Haywood HC (eds): Developmental Follow-up: Concepts, Domains, and Methods. Orlando, FL, Academic Press (in press), 1993

36. Greene T, Ernhart CB, Martier S, Sokol R, Ager J: Prenatal alcohol exposure and language development. Alcohol Clin Exp Res 14:937-945, 1990

37. Greene T, Ernhart CB, Ager J, Sokol R, Martier S, Boyd T: Prenatal alcohol exposure and cognitive development in the preschool years. Neurotoxicol Teratol 13:57-68, 1991

38. Coles CD, Brown RT, Smith IE, Platzman KA, Erickson S, Falek A: Effects of prenatal alcohol exposure at school age. I. Physical and cognitive development. Neurotoxicol Teratol 13:357-367, 1991

39. Russell M, Czarnecki DM, Cowan R, McPherson E, Mudar PJ: Measures of maternal alcohol use as predictors of development in early childhood. Alcohol Clin Exp Res 15:991-1000, 1991 